\title{
The development of swimming power
}

\author{
Giorgio Gatta ${ }^{1}$ \\ Bruno Leban² \\ Maurizio Paderi² \\ Johnny Padulo3,4,5 \\ Gian Mario Migliaccio $4,5,6$ \\ Massimiliano Pau²
}

1 Department for Life Quality Studies, Rimini Campus, University of Bologna, Bologna, Italy

2 Department of Mechanical, Chemical and Materials Engineering, University of Cagliari, Italy

3 University eCampus, Novedrate (CO), Italy

4 National Center of Medicine and Science in Sports (CNMSS), Tunis, Tunisia

5 CONI - Italian Olympic Committee, Sardinia, Italy

6 Sport Science Lab, London, UK

Corresponding author:

Johnny Padulo

University eCampus

Via Isimbardi 10

22060 Novedrate (CO), Italy

E-mail: sportcinetic@gmail.com

\section{Summary}

Purpose: the aim of this study was to investigate the effects of the transfer strength training method on swimming power. Methods: twenty male swimmers "master" were randomly allocated to strength ( $n=10, S T)$ and swimming training $(n=10, S W)$ groups. Both groups performed six-weeks training based on swimming training for SW and strength training which consisted in a weight training session immediately followed by the maximum swimming velocity. The performance in both groups was assessed by Maximal-Mechanical-ExternalPower (MMEP) before and after the six-weeks period, using a custom ergometer that provided force, velocity, and power measurement in water. $R e$ sults: a significant increased MMEP in ST group $(5.73 \%$ with $p<0.05)$ was obtained by an increased strength $(11.70 \%$ with $p<0.05)$ and a decreased velocity (4.99\% with $p>0.05)$. Conversely, in the SW group there was a decreased in MMEP $(7.31 \%$; $p<$ $0.05)$, force and velocity $(4.16 \%$, and 3.45 ; respectively $\mathrm{p}>\mathbf{0 . 0 5}$ ). Conclusion: this study showed that the transfer training method, based on combina- tion of weight training (in dry condition) immediately followed by fast swim (in water) significantly improves swimming-power in master.

KEY WORDS: ecological validity, field testing, performance, power test in water, strength training.

\section{Introduction}

The metabolic demands of the swimming competitions are very different, indeed aerobic and anaerobic systems ${ }^{1}$ are related to the race time (from $20 \mathrm{sec}$ for $25-\mathrm{m}$ to $900 \mathrm{sec}$ for $1500-\mathrm{m})$. Nevertheless, the performance of swimmers was continuously improved due the enhancement of technique ${ }^{2}$, the evolution of the facilities ${ }^{3}$ and the improvements of the physical skill of the athletes $^{2}$. Swimming action recruits many muscles for propulsion, mechanical power, and for drag contrast ${ }^{4}$. Therefore, the muscle strength plays a crucial role to increase the swim velocity ${ }^{5}$. Although some authors ${ }^{6,7}$ have shown that the adjustments related to technical movements performed in "dry conditions" using overloads, may be useful to improve the technique of the swimmers in the water, this was not confirmed by field swimmer's coaches. Currently, two methods are mainly used for strength training purposes in swimmers: "drymethods", namely with session out of water composed by exercises with loads of general type ${ }^{8-10}$, or by "simulating" the swimming movements ${ }^{11}$. The simulation approach was carried out with "aquatic-methods" training session, when the swim is overloaded with tethered 12 or tools that increase the dragging force ${ }^{4}$.

However, it is not yet entirely clear on the actual effectiveness of these methods ${ }^{1}$, as it appears difficult to increase the strength as the power of swimmers through "aquatic-methods" into load session ${ }^{13,}{ }^{14}$. Similarly, an increasing strength method obtained with "dry-methods" showed some limits on the "transferability" on specific technical swim movements ${ }^{9,} 15$. Recently, several in-water methods 5,16 were used to assess the strength and the power of the swimmers through the assessment of the drag, providing conflicting results $5,16,17$. The strength and power estimates from swimming velocity doesn't seem adequate $^{8,18,19}$ because the swimming velocity was related to muscle power, and both propulsion efficiency and drag coefficient of swimmer ${ }^{5}$. In rare cases the use of tethered test has been reported with some limitations (the swimmer cannot effectively advance in water, and thus the technical gestures are altered). 
Among the different methods of training alternating dry weights and swimming we chose the method proposed by Prof. Cometti20. Despite never having been studied with scientific rigor its principles are clear. This innovative method aimed to improve the swimmer performance, using an approach potentially valid even in other disciplines (such as Team Sport). Indeed the Cometti method $^{21}$ seems stimulate the muscle fibers using a external-load of about $80 \%$ of a one-maximum-repetition fast swimming 20,21 . The goal would be to stimulate the muscle fiber with an overload in water, that is impossible to reproduce because of the lack of "stable points of resistance". Therefore the aim of this study was to verify a Cometti training method based on mixed "dry-land phase with overloads with a series of fast swimming" on the swimming power with a specific semi-tethered swimming test.

\section{Patients and methods}

\section{Participants}

Twenty senior male master swimmers belonging to the same team were recruited for the study and randomly assigned to either the strength training (ST, $n=$ $10)$ or swimming training (SW, $n=10)$ groups. Their main anthropometric data, as well as their best performances on 100 meter crawl, are reported in Table 1. In order to be included in the study, participants had to: 1) participate in at least $90 \%$ of the training sessions (see following chapter about training program), 2) have regularly competed during the previous competitive season, and 3) possess a medical clearance. There were no dropouts from the experiments and no injuries occurred during the experimental training or testing sessions. Indoor field tests were completed in a certified swimming pool. Baseline tests started at 5:00 p.m. $\left(26.5 \pm 0.12^{\circ} \mathrm{C}\right.$, water temperature), while post-assessments were carried out at 5:00 p.m. $\left(26 \pm 0.16^{\circ} \mathrm{C}\right.$, water temperature). The participants were healthy and clear of any drug consumption. The groups were homogeneous with regard to their training status (more 10 years background competitions). Each subject was fully informed and trained about the test's procedures and

Table 1. Anthropometric data of the subjects.

\begin{tabular}{lll}
\hline VARIABLE & ST $(\boldsymbol{n = 1 0})$ & SW $(\boldsymbol{n}=10)$ \\
\hline Age (years) & $38.7 \pm 8.6$ & $32.0 \pm 6.9$ \\
Body mass $(\mathrm{kg})$ & $77.2 \pm 8.6$ & $74.9 \pm 9.2$ \\
Height $(\mathrm{cm})$ & $176.2 \pm 4.4$ & $176.4 \pm 5.8$ \\
BMI $\left(\mathrm{kg} / \mathrm{m}^{2}\right)$ & $24.8 \pm 2.4$ & $24.1 \pm 2.9$ \\
$\begin{array}{l}\text { Best time 50 } \\
\text { meters crawl (sec) }\end{array}$ & $28.9 \pm 1.4$ & $29.3 \pm 2.1$ \\
$\begin{array}{l}\text { Best time 100 } \\
\text { meters crawl (sec) }\end{array}$ & $63.4 \pm 4.4$ & $63.5 \pm 4.2$ \\
$\begin{array}{l}\text { Training experience } \\
\text { (years) }\end{array}$ & $13.5 \pm 5.8$ & $10.3 \pm 2.4$
\end{tabular}

Values are represented as means \pm SD for strength (ST) and swimming training (SW) groups. everyone gave the written informed approval to participate in the study in accordance with the guideline of the Muscle, Ligament and Tendons Journal22. All experimental procedures were approved by the University Human Research Ethics Committee, which followed the ethical principles laid out in the 2008 revision of the Declaration of Helsinki.

\section{Testing}

A parallel, two-group, randomized, longitudinal (pretest/post-test), single-blind experimental design was used. After baseline measurements, participants were randomly allocated to either the strength training (ST) or swimming training (SW) groups with an allocation ratio of one-to one ${ }^{23}$. The independent variable was "training type", so no control group was used. The study lasted 6 weeks (from September to November in pre-season) and consisted of one session of test (pre and post training) before and after one week training sessions. No additional strength, power and/or plyometric training was completed by the subjects out of the training intervention of the present study.

\section{Training outcomes}

Before and after (test- retest) the training period, participants performed one testing session of semi-tethered-swimming to assessment Maximal Mechanical External Power (MMEP). Before each testing session, participants were instructed not to eat for at least three hours before testing and not to drink coffee or beverages containing caffeine for at least eight hours before physical testing. Tests were completed at the same time of the day, with the operators unaware of the participant's allocation.

\section{Maximal Mechanical External Power Test}

The test consisted in $15 \mathrm{~m}$ all-out front-crawl swims across the pool while pulling a different load during each trial, besides the reliability of the test has been shown in previous studies to be very high (Intra-class Correlation Coefficient $>0.80$ ) as shown by DominguezCastells et al. ${ }^{24}$. After a standardized $800 \mathrm{~m}$ warm-up, the test started with a load of $45 \mathrm{~N}$. The load increased by $25 \mathrm{~N}$ for each trial. Swimmers rested for $5 \mathrm{~min}$ between 2 consecutive 5 repetitions. The protocol ended when the swimmer was not able to complete a trial. Data related to the first and last $2.5 \mathrm{~m}$ was discarded to consider only constant speed conditions ${ }^{24}$. The MMEP parameters of interest were acquired by means of a dedicated custom ergometer designed and built by Tecnologicamente S.r.I. (Italy) with the collaboration of the workshop of the Department of Mechanical, Chemical and Materials Engineering of the University of Cagliari (Italy). The ergometer used for the experimental sessions was linked to the swimmer using a belt as described in the following (Fig. 1). 


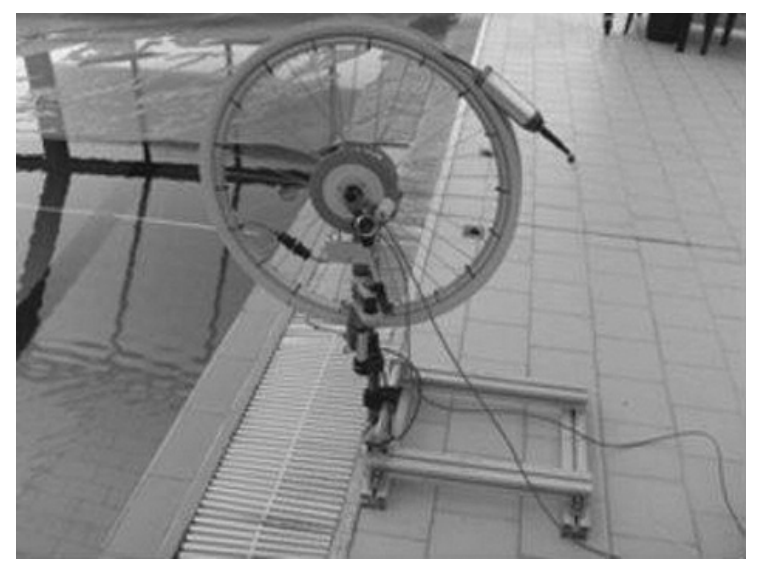

Figure 1. Ergometer device.

This device is basically composed by a 28 " wheel (acting as a drum with a winding circumference of $2092 \mathrm{~mm}$ ), a cable, two sensors (force and speed) and an electronic apparatus necessary to properly transmitted the data to a Personal Computer. The wheel is equipped with a disc brake (Shimano disc $160 \mathrm{~mm}$ diameter and Hayes Nine brake caliper) and a reflective encoder wheel with 72 pulses per turn read by an optical speed sensor (Optek OPB704). A $500 \mathrm{~N}$ miniature tension-compression load cell (F2220, Tecsis $\mathrm{GmbH}$, Germany) was hosted inside an aluminum cylindrical $(160 \mathrm{~mm}$ long, $47 \mathrm{~mm}$ diameter with a nose cone to minimize the hydrodynamic resistance effects) that act as waterproof case and was connected to the swimmer through a belt equipped with a system composed by a light aluminum bar and four twines. The load-cell signal is conditioned and powered by a Mecostrain 2038 module embedded in the cylindrical aluminum case.

Prior to the tests, a calibration curve hydraulic pressure vs resistant force was obtained using calibrated weights (corresponding to a $10-150 \mathrm{~N}$ force range). Both force transducer and speed sensor signals were properly acquired by a National Instruments DAQ Module USB 6009 (8 channels, 14-Bit, 48 kS/s). A custom routine was developed in the National Instruments LabView ${ }^{\circledR}$ environment to collect and store data in form of ASCII files during the trial. The resulting files were then post-processed with a Matlab ${ }^{\mathrm{TM}} 10$ software routine that transforms the raw data into a four-vectors text file containing time, traveled distance, instantaneous force, and speed values.

\section{Training program}

The training program was performed during six weeks, divided in three sessions for both groups in according to Cometti method ${ }^{21}$. All participants (ST SW) after 15 minutes of standardized warm-up carried out the same set of exercises in water, that comprises several sprints (Tab. 2) in front crawl at maximum velocity with sets and recovery balanced. Each swimming session had a duration of approximately 2 hours and was repeated 5 times per week. During the swimming training the same distance was performed for both groups (ST - SW).

Particularly, ST group were performed as suggested by Cometti 20,21 , the strength training program (Tab. 3) during swimming training (mixed: weight training swim maximum velocity and vice versa). The one repetition maximum (1-RM) test on bench press was conducted to determine maximal upper body strength as recommended by Padulo et al. ${ }^{25}$ one week before the training. Particularly, during the exercise with a load of $(85 \% 1-\mathrm{RM})^{6}$ or body load, subjects were asked to perform 6 fast repetitions ${ }^{6}$ according to Cometti method 20,21 . To minimize the effect of the passive recovery 20,21 in-between weight training and swimming exercises ( 5-s), each participant was encouraged by the coach.

\section{Statistical analyses}

Normality of the data was verified using the ShapiroWilk test. The null hypothesis was tested to reveal no difference between groups using multiple unpaired $t$ tests. A two-way mixed analysis of variance (ANOVA) was used on each continuous dependent variable. The independent variables included one betweenparticipants factor, training intervention with two levels (ST and SW), and one within-participant factor time, with two levels (pre-test and post-test). ANOVAs was used to test the null hypothesis of no difference in the change over time between ST and SW (training intervention $\times$ time interaction), and the null hypothesis of no difference in the change over time in response to the training intervention (main effect for time). With this statistical design, the following variables were analyzed: MMEP (Watt), Force (N) and speeds $\left(\mathrm{m} \cdot \mathrm{s}^{-1}\right)$. The effect sizes were also calculated (eta squared, $\eta^{2}$ ) for better interpretation of the results and $p$-value $<0.05$ was considered significant. Test-retest reliability ${ }^{26}$ was satisfied in previous study ${ }^{24}$ using the Intra-class Correlation Coefficient (ICC). Statistical analysis was performed using Sigma Plot $^{\mathrm{TM}}$ software 11.0 (Systat Software, Tulsa, OK).

\section{Results}

All data are reported in Table 4. There was no difference between groups at baseline conditions for age $(p=0.070)$, height $(p=0.932)$, body mass $(p=$ $0.570)$, BMI $(p=0.524)$, swimming performance on $50-\mathrm{m}(p=0.563)$ and $100-\mathrm{m}(p=0.992)$.

ANOVA with repeated measures revealed differences between the two groups in MMEP: $F_{(1,19)}=2.403, p=$ 0.139 , and the interaction training type $\times$ time $F_{(1,19)}=$ 11.367, $p=0.003$, while the Force showed $F_{(1,19)}=$ 3.227, $p=0.089\left(\eta^{2}=0.152\right)$, and the interaction training type $\times$ time $F_{(1,19)}=11.107, p=0.004\left(\eta^{2}=\right.$ 0.382). Speed: $F_{(1,19)}=0.443, p=0.514\left(\eta^{2}=0.024\right)$, and the interaction training type $\times$ time $F_{(1,19)}=0.168$, $p=0.686\left(\eta^{2}=0.009\right)$. Data from the ST revealed an 
improvement of force and MMEP: $11.70 \%(p=0.012)$ and $5.73 \%(p=0.050)$ respectively, while the velocity decreased $4.99 \%(p=0.070)$ with respect to baseline conditions (Fig. 2). Swimming training in SW group revealed a reduction in all variables studied (Tab. 4).

\section{Discussion}

The results show that the transfer is effective an improving MMEP in masters male swimmers and might represent a technique useful to achieve better performance. In the last years, several authors ${ }^{27,} 28$ investigated new methods to improve the swimming perfor- mances. Particularly, in the swimming history, several reasons have limited scientific knowledge in water sports. Many technical approach were due to the environment that requires special equipment; in fact, it is still difficult to validate the different training methods so far tested in swimming ${ }^{14}$. Dominguez-Castells et al. ${ }^{24}$ showed for the first time a new interesting method to assessing mechanical power output as a reliable predictor of performance of the swimmers ${ }^{24}$; for this aim the Dominguez-Castells methodology has been used in the present investigation.

Our findings are partly in agreement with the results of Morouco ${ }^{14}$, who showed the existence of a relationship between dry land strength and power mea-

Table 2. Swimming training program for ST and SW groups.

\begin{tabular}{|c|c|c|c|c|c|c|}
\hline \multirow[b]{2}{*}{ Week-day } & \multicolumn{2}{|c|}{ First Trial } & \multicolumn{2}{|c|}{ Second Trial } & \multicolumn{2}{|c|}{ Third Trial } \\
\hline & ST & $s w$ & ST & $s w$ & $S T$ & $s w$ \\
\hline Monday & $\begin{array}{l}600-\mathrm{m} \mathrm{fc}+ \\
\text { block } 1\end{array}$ & $\begin{array}{l}600-\mathrm{m} \mathrm{fc}=8 \times 50-\mathrm{m} \mathrm{fc} \\
(\text { rec } 1 \text { '30") }+8 \times 25-\mathrm{m} \mathrm{fc} \\
\left(\operatorname{rec} 45^{\prime \prime}\right)\end{array}$ & $\begin{array}{l}600-\mathrm{m} \mathrm{fc}+ \\
\text { block } 2\end{array}$ & $\begin{array}{l}600-\mathrm{m} \mathrm{fc}=8 \times 50-\mathrm{m} \\
(\text { rec } 1 \text { '30") }+8 \times 25-\mathrm{m} \\
\mathrm{fc}\left(\operatorname{rec} 45^{\prime \prime}\right)\end{array}$ & $\begin{array}{l}700-\mathrm{m} \mathrm{fc}+ \\
\text { block } 3\end{array}$ & $\begin{array}{l}700-\mathrm{m} \mathrm{fc}= \\
2 \times(6 \times 25-\mathrm{m} \\
\text { fc }- \text { rec } 45 "+ \\
4 \times 50-\mathrm{m} \mathrm{fc}- \\
\text { rec } 1 \text { ' } 30 ")\end{array}$ \\
\hline Tuesday & \multicolumn{2}{|c|}{$\begin{array}{l}1600-\mathrm{m} \text { fc }=8 \times 100-\mathrm{m} \text { fc }(\text { rec } 10 ")+ \\
4 \times 200-\mathrm{m} \text { fc }(\text { rec } 15 ")\end{array}$} & \multicolumn{2}{|c|}{$\begin{array}{l}1800-m \text { fc }=8 \times 100-m \text { fc }(\text { rec } 10 ")+ \\
5 \times 200-m \text { fc }(\text { rec } 15 ")\end{array}$} & \multicolumn{2}{|c|}{$\begin{array}{l}1600-\mathrm{m} \mathrm{fc}=8 \times 100-\mathrm{m} \mathrm{fc} \\
(\text { rec10") }+4 \times 200-\mathrm{m} \mathrm{fc} \\
(\text { rec15") }\end{array}$} \\
\hline Wednesday & $\begin{array}{l}600-\mathrm{m} \mathrm{fc}+ \\
\text { block } 1\end{array}$ & $\begin{array}{l}600-\mathrm{m} \mathrm{fc}=8 \times 50-\mathrm{m} \text { fc } \\
(\text { rec } 1 \text { '30") }+8 \times 25-\mathrm{m} \mathrm{fc} \\
\left(\text { rec } 45^{\prime \prime}\right)\end{array}$ & $\begin{array}{l}600-\mathrm{m} \mathrm{fc}+ \\
\text { block } 2\end{array}$ & $\begin{array}{l}600-\mathrm{m} \mathrm{fc}=8 \times 50-\mathrm{m} \\
(\text { rec } 1 ' 30 ")+8 \times 25-\mathrm{m} \mathrm{fc} \\
\left(\text { rec } 45^{\prime \prime}\right)\end{array}$ & $\begin{array}{l}700-\mathrm{m} \mathrm{fc}+ \\
\text { block } 3\end{array}$ & $\begin{array}{l}700-\mathrm{m} \mathrm{fc}= \\
2 \times(6 \times 25-\mathrm{m} \text { fc } \\
- \text { rec } 45^{\prime \prime}+ \\
4 \times 50-\mathrm{m} \mathrm{fc}- \\
\text { rec } 1 \text { ' } 30 ")\end{array}$ \\
\hline Thursday & \multicolumn{2}{|c|}{$\begin{array}{l}3100-\mathrm{m} \text { fc }=3 \times 300-\mathrm{m} \text { fc (rec } 15 ”)+ \\
5 \times 200-\mathrm{m}\left(\text { rec } 15^{\prime \prime}\right)+3 \times 400-\mathrm{m} \mathrm{fc} \\
(\text { rec } 20 ")\end{array}$} & \multicolumn{2}{|c|}{$\begin{array}{l}3100-\mathrm{m} \text { fc }=3 \times 300-\mathrm{m} \text { fc }\left(\operatorname{rec} 15^{\prime \prime}\right) \\
+5 \times 200-\mathrm{m}\left(\text { rec } 15^{\prime \prime}\right)+ \\
3 \times 400-\mathrm{m} \mathrm{fc}(\operatorname{rec} 20 ")\end{array}$} & \multicolumn{2}{|c|}{$\begin{array}{l}3100-\mathrm{m} \text { fc }=3 \times 300-\mathrm{m} \text { fc }(\mathrm{rec} \\
\left.15^{\prime \prime}\right)+5 \times 200-\mathrm{m}(\text { rec 15") }+ \\
3 \times 400-\mathrm{m} \mathrm{fc}(\text { rec 20") }\end{array}$} \\
\hline Friday & $\begin{array}{l}600 \mathrm{sl}+ \\
\text { block } 1\end{array}$ & $\begin{array}{l}600-\mathrm{m} \mathrm{fc}=8 \times 50-\mathrm{m} \mathrm{fc} \\
(\text { rec 1'30") }+8 \times 25-\mathrm{m} \mathrm{fc} \\
(\text { rec 45”) }\end{array}$ & $\begin{array}{l}600-\mathrm{m} \mathrm{fc}+ \\
\text { block } 2\end{array}$ & $\begin{array}{l}600-\mathrm{m} \mathrm{fc}=8 \times 50-\mathrm{m} \\
(\text { rec } 1 \text { '30") }+8 \times 25-\mathrm{m} \\
\text { fc (rec 45") }\end{array}$ & $\begin{array}{l}700-\mathrm{m} \mathrm{fc}+ \\
\text { block } 3\end{array}$ & $\begin{array}{l}700 \mathrm{c} 1 \mathrm{sl}=2 \times \\
(4 \times 50 \mathrm{sl} \text { rec } \\
1 ' 30 "+6 \times 25 \mathrm{sl} \\
\left.\text { rec } 45^{\prime \prime}\right)\end{array}$ \\
\hline Monday & $\begin{array}{l}600 \mathrm{sl}+ \\
\text { block } 1\end{array}$ & $\begin{array}{l}600-\mathrm{m} \mathrm{fc}=8 \times 50-\mathrm{m} \mathrm{fc} \\
(\text { rec 1'30") }+8 \times 25-\mathrm{m} \mathrm{fc} \\
(\text { rec 45”) }\end{array}$ & $\begin{array}{l}600-\mathrm{m} \mathrm{fc}+ \\
\text { block } 2\end{array}$ & $\begin{array}{l}600-\mathrm{m} \text { fc }=8 \times 50-\mathrm{m} \\
(\text { rec } 1 \text { '30") }+8 \times 25-\mathrm{m} \\
\left.\text { fc (rec } 45^{\prime \prime}\right)\end{array}$ & $\begin{array}{l}700-\mathrm{m} \mathrm{fc}+ \\
\text { block } 3\end{array}$ & $\begin{array}{l}700-\mathrm{m} \mathrm{fc}= \\
2 \times(6 \times 25-\mathrm{m} \\
\text { fc }- \text { rec } 45 "+ \\
4 \times 50-\mathrm{m} \mathrm{fc}- \\
\text { rec } 1 \text { ' } 30 ")\end{array}$ \\
\hline Tuesday & \multicolumn{2}{|c|}{$\begin{array}{l}2000-m=2 \times(3 \times 100-m \text { fc }- \text { rec } 10 "+ \\
2 \times 150-m \text { fc }- \text { rec } 15 "+2 \times 200-m- \\
\text { rec } 20 ")\end{array}$} & \multicolumn{2}{|c|}{$\begin{array}{l}2000-m=2 \times(3 \times 100-m \text { fc }- \text { rec } 10 "+ \\
2 \times 150-m \text { fc }- \text { rec } 15 "+2 \times 200-m- \\
\text { rec } 20 ")\end{array}$} & \multicolumn{2}{|c|}{$\begin{array}{l}2500-m=2 \times(4 \times 100-m-r e c \\
10 "+3 \times 150-m-\text { rec } 15 "+ \\
2 \times 200-m-\text { rec } 20 ")\end{array}$} \\
\hline Wednesday & $\begin{array}{l}600 \mathrm{sl}+ \\
\text { block } 1\end{array}$ & $\begin{array}{l}600-\mathrm{m} \mathrm{fc}=8 \times 50-\mathrm{m} \mathrm{fc} \\
(\text { rec } 1 \text { '30") }+8 \times 25-\mathrm{m} \mathrm{fc} \\
(\text { rec 45") }\end{array}$ & $\begin{array}{l}600-\mathrm{m} \mathrm{fc}+ \\
\text { block } 2\end{array}$ & $\begin{array}{l}600-\mathrm{m} \mathrm{fc}=8 \times 50-\mathrm{m} \\
(\text { rec } 1 \text { ' } 30 ")+8 \times 25-\mathrm{m} \\
\mathrm{fc}\left(\text { rec } 45^{\prime \prime}\right)\end{array}$ & $\begin{array}{l}700-\mathrm{m} \mathrm{fc}+ \\
\text { block } 3\end{array}$ & $\begin{array}{l}700-\mathrm{m} \mathrm{fc}= \\
2 \times(6 \times 25-\mathrm{m} \\
\text { fc }- \text { rec } 45^{\prime \prime}+ \\
4 \times 50-\mathrm{m} \mathrm{fc}- \\
\text { rec } 1 \text { ' } 30 ")\end{array}$ \\
\hline Thursday & \multicolumn{2}{|c|}{$2000-\mathrm{m}$ fc = free-low intensity } & \multicolumn{2}{|c|}{ 2000-m fc = free-low intensity } & \multicolumn{2}{|c|}{$2500-\mathrm{m} \mathrm{fc}=$ free-low intensity } \\
\hline Friday & \multicolumn{2}{|c|}{$\begin{array}{l}2500-m=2 \times(1 \times 100-m \text { fc }- \text { rec } 10 "+ \\
1 \times 200-m \text { fc }- \text { rec } 15 "+1 \times 250-m \text { bs }- \\
\text { rec } 15 "+1 \times 300-m \text { me rec } 15 "+ \\
1 \times 400-m \text { me }- \text { rec } 20 ")\end{array}$} & \multicolumn{2}{|c|}{$\begin{array}{l}3000-m=3 \times(1 \times 100-m \text { fc }- \text { rec } 10 " \\
+1 \times 200-m \text { fc }- \text { rec } 15 "+1 \times 300-m \\
\text { me }- \text { rec } 15^{\prime \prime}+1 \times 400-m \text { me }- \\
\text { rec } 20 ")\end{array}$} & \multicolumn{2}{|c|}{$\begin{array}{l}3000-m=3 \times(1 \times 100-m \text { fc }- \\
\text { rec } 10 "+1 \times 200-m \text { fc }- \text { rec } \\
15^{\prime \prime}+1 \times 300-m \text { me }- \text { rec } 15^{\prime \prime} \\
+1 \times 400-m \text { me- rec } 20 ")\end{array}$} \\
\hline
\end{tabular}

Note: six weeks swimming training program divided in three trials (two weeks per trial) for ST and SW in front craw (fc), backstroke (bs) and medley (me) styles. To simply ST group program in the trials was included only the total distance (see Table III) and added blocks $(1,2,3)$. 
Table 3. Strength training for ST group.

$1^{\text {st }}$ Trial

- 6 sets $\times(6 \times$ pushing speed on bench press $(85 \% 1-\mathrm{RM})+1 \times 25-\mathrm{m} \mathrm{fc})$ with (intra-sets) rec $1 \times 50-\mathrm{m}$ free-low speed and $200-\mathrm{m}$ fc in final sets

- 6 sets $\times\left(8 \times\right.$ Abdominal Exercises (lower limb $\left.90^{\circ}\right)$ with $5 \mathrm{~kg}$ on the chest blocked by arms $+1 \times 50-\mathrm{m}$ fc) with (intra-sets) rec $1 \times 50-m$ free-low speed and $200-m$ fc in final sets

- 6 sets $\times(6 \times$ simulation craw with Double Lat Machine $(5 \mathrm{~kg})$ in standing position $+1 \times 25-\mathrm{m} \mathrm{fc})$ with (intra-sets) rec $1 \times 50-\mathrm{m}$ free-low speed and $200-\mathrm{m}$ fc in final sets

\section{$2^{\text {nd }}$ Trial}

- 6 sets $\times(6 \times$ traction (prone position) on bench press $(85 \% 1-\mathrm{RM})+1 \times 25-\mathrm{m}$ fc) with (intra-sets) rec $1 \times 50-\mathrm{m}$ free-low speed and 200-m fc in final sets

- 6 sets $\times(6 \times$ Dumbbell Lateral Raise $(42.5 \% 1-\mathrm{RM}$ for arm $)+1 \times 50-\mathrm{m} \mathrm{fc})$ with (intra-sets) rec $1 \times 50-\mathrm{m}$ free-low speed and $200-\mathrm{m}$ fc in final sets

- 6 sets $\times(6 \times$ Pullover with barbell at bench $(85 \% 1-\mathrm{RM})+1 \times 25-\mathrm{m} \mathrm{fc})$ with (intra-sets) rec $1 \times 50-\mathrm{m}$ free-low speed and $200-\mathrm{m}$ fc in final sets

$3^{\text {rd }}$ Trial

- 7 sets $\times(6 \times$ max traction on the bar (body weight) $+1 \times 25-m$ fc) with (intra-sets) rec $1 \times 50-m$ free-low speed and 200-m fc in final sets

- 7 sets $\times(6 \times$ Dumbbell Cross Raise $(42.5 \% 1-\mathrm{RM}$ for arm $)+1 \times 50-\mathrm{m} \mathrm{fc})$ with (intra-sets) rec $1 \times 50-\mathrm{m}$ free-low speed and $200-\mathrm{m}$ fc in final sets

- 7 sets $\times(6 \times$ simulation craw with Double Lat Machine $(5 \mathrm{~kg})$ in standing position $+1 \times 25-\mathrm{m} \mathrm{fc})$ with (intra-sets) rec $1 \times 50-m$ free-low speed and $200-m$ fc in final sets

Single block indentify the single sessions of workout on strength training (mixed: weight training - swim maximum velocity in front craw (fc) and vice-versa) during treatment (see Table 2).

Table 4. Results of absolute and percentage for each variables after six weeks training.

\begin{tabular}{|c|c|c|c|c|c|c|c|c|c|}
\hline \multirow[t]{2}{*}{ Group } & \multirow[b]{2}{*}{ Pre } & \multicolumn{3}{|l|}{ MMEP (w) } & \multicolumn{3}{|l|}{ Force (N) } & \multicolumn{2}{|c|}{ Velocity $\left(m \cdot s^{-1}\right)$} \\
\hline & & Post & $(\Delta \%)$ & Pre & Post & $(\Delta \%)$ & Pre & Post & $(\Delta \%)$ \\
\hline ST & $70.31 \pm 18.36$ & $74.34 \pm 19.37$ & $5.73^{*}$ & $77.16 \pm 13.43$ & $86.19 \pm 16.84$ & $11.70 \dagger$ & $0.90 \pm 0.09$ & $0.86 \pm 0.10$ & -4.99 \\
\hline sw & $62.48 \pm 17.07$ & $57.92 \pm 15.88$ & $-7.31^{*}$ & $71.57 \pm 16.00$ & $68.59 \pm 13.38$ & -4.16 & $0.87 \pm 0.09$ & $0.84 \pm 0.10$ & -3.45 \\
\hline
\end{tabular}

Values are expressed as mean \pm SD for strength training (ST) and swimming training (SW) groups. $\left(^{*}\right) p<0.05-(\dagger) p<$ 0.01 versus baseline conditions.

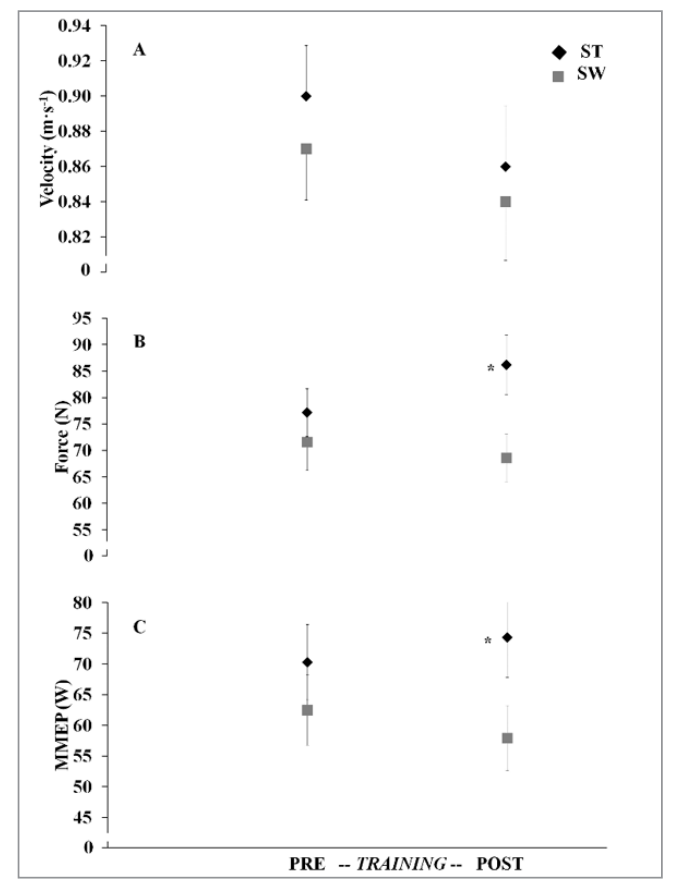

Figure 2. The effect of the training (means and SE) respect baseline conditions for: MMEP (watt), Force $(\mathrm{N})$ and speeds $\left(\mathrm{m} \cdot \mathrm{s}^{-1}\right)$ in both groups (ST $-\mathrm{SW})$. “*” $\mathrm{p}<0.05$ represent significant differences between pre and post training. 
sured during swimming performance ${ }^{14,29}$. In dry conditions Morouco studied upper-lower limb muscle strength and revealed high associations between swimming performance vs muscular strength method $^{29}$. From our point of view, our work tries to change from that performed by Moruco particularly in two key points: entering the fast movements with weights ( $85 \% 1-\mathrm{RM})$, and mixed training (weight training immediately followed by swimming sprints).

\section{Force}

Considering the effects of this method 20,21 , the results (Fig. 2B) indicate that mixed training increased the strength in ST group by $9.03-\mathrm{N}(11.70 \%$ increase). This effect could be emphasized especially for short time trials or several track competitions (e.g. 50 - 100 meters) where the results are often highly contested with close finishes. The present study results are in line with Schmidtbleicher et al. ${ }^{30}$ and Padulo et al. ${ }^{6}$ that have shown that few repetitions and maximal loads (> 80\% 1-RM) induced recruitment of fast-twitch motor units ${ }^{30}$ and increased muscle strength $(10.20 \%$ $\mathrm{p}<0.05)^{6}$ for ST, compared to repetitions with low loads and free speed. This interesting improvement of the strength in ST obtained with a mixed model training can be analyzed as a further deepening of the understanding of the strength development in swimmers $^{13}$. It seems that the adaptations of the swim intensity stimulate more than the mechanisms that trigger of aerobic capacity and limiting the development of the contractile muscle structure.

Conversely a decreased $4.16 \%$ in SW does not stimulate fairly motor units. Indeed, swimmers train over many miles daily, and in the case of master swimmers this is more evident, at low intensity. Moreover the force applied in water requires particular sensitivity and gradation of effort ${ }^{31}$. The training for an enhanced MMEP, emphasizing neural adaptations, led to significant changes in rate of force development using weight training. These results showed an increased in rate of force development and thus power production, rather than the increased swimming workout. For this reason the MMEP was no changed in SW group. These results in the SW group can be related to lower stimulation of muscle strength with only swimming as a main training activity.

\section{Velocity}

The swimming speed was measured during the semi-tethered test at maximal load, because crucial component of the power value obtained. Concerning the maximum speed (Fig. 2A) the MMEP showed a dropping of $\sim 5 \%\left(0.04 \mathrm{~m} \cdot \mathrm{sec}^{-1}\right)$ in both groups (ST $\mathrm{SW})$ that represented a decrease with respect to the pre-test value, resulting from the training interventions. Moreover, the velocity reported small differences $(\sim 5 \%)$ with no significant effects in both groups, in ST (min/max: $\left.0.74-1.04 \mathrm{~m} \cdot \mathrm{sec}^{-1}\right)$ this ef- fects showed a shift on low speed of maximal power output $(5.73 \%$ with $p<0.05)$. In according with Morouco et al. ${ }^{29}$ the velocity must not be assessed as a negative effect on swim performances because this velocity represent the ratio between power output and force in MMEP.

\section{Maximal-mechanical-external-power (MMEP)}

The results showed (Fig. 2C) an increase of 4.04-w (MMEP), that representing $5.73 \%$ of pre-test values in ST. Improvements in ST of MMEP could be related to force production ${ }^{32}$ more than in SW. The increased MMEP in ST on is in agreement with explosive movements on the neuromuscular systems ${ }^{33}$. In this regard, MMEP showed more accuracy in relationship to the ecological validity because in our semi-tethered test the swimmers performed 15 meters of swimming with external loads. As confirmed by DominguezCastells et al. ${ }^{24}$ and Morouco et al. ${ }^{29}$, the power test in swimming were altered when each subject were constrained to swim without wear on.

\section{Combined effects of the variables studied}

The innovative method suggested by Cometti highlights that for water sports, mixed training (land and water) is favorable to stimulate muscle strength, in relationship at the combination of movement in dry conditions (weight training) without other resistance as Drag. In addition, the various phases of eccentric/ concentric ${ }^{34}$ contractions during exercise in land are not altered by the hydrostatic pressure. On the same topic, di Prampero showed that the greatest fraction of the energy expenditure is utilized to overcome water resistance or Drag ${ }^{17}$. The 6 weeks explosive-type strength training resulted in considerable improvements in selected neuromuscular characteristics, although a large volume of endurance training was performed at the same time. An hypothesis is that training-induced alterations in neural control during stretch-shortening cycle exercises (such as running and jumping $)^{35}$ might take place in both voluntary activation, inhibitory and facilitatory reflexes ${ }^{36}$.

From our point of view it is not clear if MMEP and strength increased in the ST, obtained through an intense workout of 6 weeks training with combinations "weight and swim training", has to be considered an important value to satisfy the research of mayor higher power. But again emphasizes how difficult it is to develop strength in the sport of swimming, as reported in considerations of other authors ${ }^{13,37 .}$

We can conclude that many problems related to the development of strength in swimmers are to be found right on the most appropriate way to raise awareness of the motor gesture in the aquatic environment. The Cometti method 20,21 that we tested in this work, proposes to include in its start-up phase muscle fast swimming immediate steps to address this problem. In our opinion, there are still elements to be explored as future 
developments mainly on the most appropriate periodization of the workload proposed. We believe that the work we propose is feasible to very experienced athletes and that, in its intensity, can give the most important effects of improvement after an appropriate period of tapering, as also proposed by other authors 28,37 .

\section{Acknowledgements}

The authors gratefully thank all athletes who took part in the study.

\section{Competing interests}

The authors declare no conflict of interest related to the present manuscript.

\section{Funding}

This study was supported by the Sardinian Regional Committee of the Italian Olympic Committes (CONI) within the framework of the "Laboratory of Sport" project.

\section{Authors Contribution}

Giorgio Gatta (Principal investigator and testing) Bruno Leban (Mechanical engineer made custom device to perform swim power test in water and testing) Maurizio Paderi (Mechanical engineer made custom device to perform swim power test in water and testing), Johnny Padulo (experimental approach, statistical analysis, writing) Gian Mario Migliaccio (Testing in water and collected data) Massimiliano Pau (Supervisor and Testing).

\section{Reference}

1. Toussaint HM, Hollander AP. Energetics of competitive swimming. Implications for training programmes. Sports Med. 1994;18(6):384-405.

2. Nevill AM, Whyte GP, Holder RL, Peyrebrune M. Are there limits to swimming world records? Int J Sports Med. 2007;28(12): 1012-1017.

3. Gatta G, Zamparo P, Cortesi M. Effect of swim-cap model on passive drag. J Strength Cond Res. 2013; 27(10):2904-2908.

4. Toussaint HM, Vervoorn K. Effects of specific high resistance training in the water on competitive swimmers. Int J Sports Med. 1990;11(3):228-233.

5. Toussaint HM, Beek PJ. Biomechanics of competitive front crawl swimming. Sports Med. 1992; 13(1):8-24.

6. Padulo J, Mignogna P, Mignardi S, Tonni F, D'Ottavio S. Effect of different pushing speeds on bench press. Int J Sports Med. 2012;33(5):376-380.

7. Sale DG. Neural adaptation to resistance training. Med Sci Sports Exerc. 1988;Suppl:135-145.

8. Strass D. Effects of maximal strength training on sprint performance of competitive swimmers. In: Swimming Science V Eds: Ungerechts, B E , Wilke, K and Reischle, K Spon Press, London. 1999;149-156.

9. Tanaka H, Costill DL, Thomas R, Fink WJ, Widrick JJ. Dry- land resistance training for competitive swimming. Med Sci Sports Exerc. 1993;25(8):952-959.

10. Trappe S, Pearson D. Effects of weight assisted dry-land strength training on swimming performance. J Strength Cond Res. 1994; 8(4):209-213.

11. Sharp RL, Troup JP, Costill DL. Relationship between power and sprint freestyle swimming. Med Sci Sports Exerc. 1982;14(1):53-56.

12. Girold S, Calmels P, Maurin D, Milhau N, Chatard JC. Assisted and resisted sprint training in swimming. J Strength Cond Res. 2006;20(3):547-554.

13. Aspenes ST, Karlsen T. Exercise-training intervention studies in competitive swimming. Sports Med. 2012;42(6):527-543.

14. Moruco PG, Marinho DA, Amaro NM, Peez-Turpin JA, Marques MC. Effects of dry-land strength training on swimming performance: a brief review. J Hum Sport Exerc. 2012; 7(2):553-559.

15. Neufer PD, Costill DL, Fielding RA, Flynn MG, Kirwan JP. Effect of reduced training on muscular strength and endurance in competitive swimmers. Med Sci Sports Exerc. 1987; 19(5): 486-490.

16. Kolmogorov SV, Duplishcheva OA. Active drag, useful mechanical power output and hydrodynamic force coefficient in different swimming strokes at maximal velocity. J Biomech. 1992;25(3):311-318.

17. Di Prampero PE. The energy cost of human locomotion on land and in water. Int J Sports Med. 1986; 7(2):55-72.

18. Girold S, Maurin D, Dugue B, Chatard JC, Millet G. Effects of dry-land vs. resisted- and assisted-sprint exercises on swimming sprint performances. J Strength Cond Res. 2007; 21(2):599-605.

19. Tanaka H, Swensen $T$. Impact of resistance training on endurance performance. A new form of cross-training? Sports Med. 1998;25(3):191-200.

20. Cometti G. Muscolation et natation. UFR STAPS, Dijon 1990.

21. Cometti G. Les methods moderns de muscolatio. UFR STAPS, Dijon (edizione italiana Calzetti Mariucci Perugia 1997) 1988.

22. Padulo J, Oliva F, Frizziero A, Maffulli N. Muscles, Ligaments and Tendons Journal. Basic principles and recommendations in clinical and field science research. MLTJ. 2013;4:250-252.

23. Schulz KF, Grimes DA. Generation of allocation sequences in randomised trials: chance, not choice. Lancet. 2002;359 (9305):515-519.

24. Dominguez-Castells R, Izquierdo M, Arellano R. An updated protocol to assess arm swimming power in front crawl. Int $J$ Sports Med. 2013; 34(4):324-329.

25. Padulo J, Laffaye G, Chaouachi A, Chamari K. Bench Press exercise: the key points. J Sports Med Phys Fitness. 2014. [Epub ahead of print].

26. Hopkins WG. Measures of reliability in sports medicine and science. Sports Med. 2000; 30(1):1-15.

27. Hawley JA, Williams MM, Vickovic MM, Handcock PJ. Muscle power predicts freestyle swimming performance. Br J Sports Med. 1992;26(3):151-155.

28. Mujika I, Chatard JC, Busso T, Geyssant A, Barale F, Lacoste $\mathrm{L}$. Effects of training on performance in competitive swimming. Can J Appl Physiol. 1995;20(4):395-406.

29. Morouco P, Neiva H, Gonzalez-Badillo JJ, Garrido N, Marinho $\mathrm{DA}$, Marques MC. Associations between dry land strength and power measurements with swimming performance in elite athletes: a pilot study. J Hum Kinet. 2011;29A:105-112.

30. Schmidtbleicher D, Haralambie G. Changes in contractile properties of muscle after strength training in man. Eur J Appl Physiol Occup Physiol. 1981;46(3):221-228.

31. Kraemer WJ, Fry AC. Strength testing: Development and evaluation of methodology. Physiological assessment of human fitness 1995; In P. Maud \& C. Foster (Champaign, IL: Human Kinetics.):115-138. 
32. Staron RS, Malicky ES, Leonardi MJ, Falkel JE, Hagerman FC, Dudley GA. Muscle hypertrophy and fast fiber type conversions in heavy resistance-trained women. Eur J Appl Physiol Occup Physiol. 1990; 60(1):71-79.

33. McBride JM, Triplett-McBride T, Davie AJ, Abernethy PJ, Newton RU. Characteristics of titin in strength and power athletes. Eur J Appl Physiol. 2003;88(6):553-557.

34. Padulo J, Laffaye G, Ardigo LP, Chamari K. Concentric and Eccentric: Muscle Contraction or Exercise? J Hum Kin. 2013;37:5-6.
35. Padulo J, Tiloca A, Powell D, Granatelli G, Bianco A, Paoli A. EMG amplitude of the biceps femoris during jumping compared to landing movements. Springerplus. 2013;2:520.

36. Hakkinen K, Kallinen M. Distribution of strength training volume into one or two daily sessions and neuromuscular adaptations in female athletes. Electromyogr Clin Neurophysiol. 1994;34(2):117-124.

37. Garrido G, Marinho DA, Reis VC, et al. Does combined dry land strength and aerobic training inhibit performance of young competitive swimmers? J Sports Sci Med. 2010;9:300-310. 